\title{
Caracterização físico-química de frutos de biri-biri (Averrhoa bilimbi L.)
}

\author{
Emmanuelle Rodrigues Araújo ${ }^{1 *}$ \\ Lânia Isis Ferreira Alves ${ }^{1}$ \\ Elizanilda Ramalho do Rêgo ${ }^{1}$ \\ Maílson Monteiro do Rêgo ${ }^{1}$ \\ Juliana Pereira de Castro ${ }^{2}$ \\ Moryb Jorge Lima da Costa Sapucay ${ }^{1}$

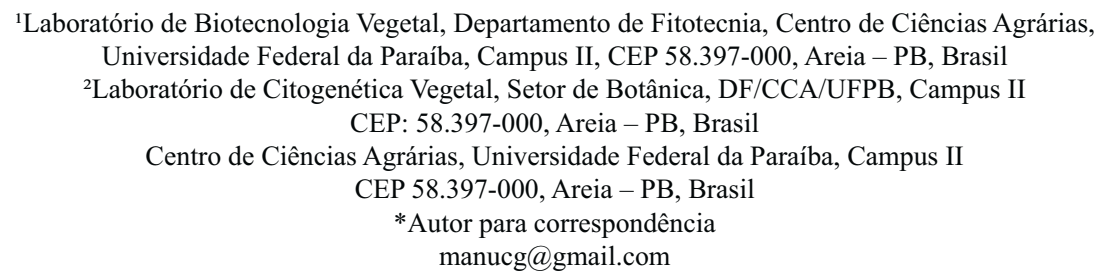

Submetido em 10/02/2009

Aceito para publicação em 03/07/2009

\section{Resumo}

O objetivo deste trabalho foi caracterizar quimicamente os frutos de biri-biri (Averrhoa bilimbi L.) coletados em diferentes estádios de maturação. Foram avaliadas as seguintes características morfométricas e químicas do fruto: peso, número de sementes, comprimento, largura maior e menor, $\mathrm{pH}$, sólidos solúveis totais, acidez titulável e vitamina C. Os teores de sólidos solúveis totais variaram de 2,35 a 3,23 Brix, sendo maiores em frutas de biri-biri maduras, assim como os valores de acidez, que variam de 1,15 a 1,66g/100 $\mathrm{g}^{-1}$, em frutos verdes e maduros, respectivamente. Entretanto os níveis de vitamina $\mathrm{C}$ foram mais elevados nos frutos verdes, porém não apresentaram diferença significativa entre os três níveis de maturação avaliados.

Unitermos: bilimbi, composição química, planta medicinal

\section{Abstract}

Physical-chemical characterization of fruits of Biri-biri (Averrhoa bilimbi L.). The aim of this work was to analyze the physical and chemical characteristics of "biri-biri" fruits (Averrhoa bilimbi L.) collected at different maturation stages. The following fruit morphometrics and chemical characters were analyzed: weight, number of seeds, length, major and minor width, $\mathrm{pH}$, the soluble content of solids (TSS), titrable acidity and vitamin C. The soluble content of solids showed values from 2.32 to $3.23^{\circ} \mathrm{Brix}$, being higher in ripe fruits and correlating with the values for acidity which varied from 1.15 to $1.66 \mathrm{~g} / 100 \mathrm{~g}^{-1}$ in green and ripe fruits, respectively. However the levels of vitamin $\mathrm{C}$ were higher in green fruits, although there were no significant differences at mature levels.

Keywords: "bilimbi”, chemical composition, medicinal plant 


\section{Introdução}

A avaliação da produtividade é essencial no melhoramento genético de plantas. Entretanto, nas espécies frutíferas, além da produtividade, a qualidade dos frutos é também de grande importância, por determinar a aceitação do produto e ter grande influência no preço obtido. Essa qualidade do fruto é um termo amplo que engloba dimensões, coloração, sabor aroma, rendimento de polpa e outros atributos para os quais o consumidor é sensível (Albuquerque et al., 2002). Os mercados mundiais passaram a exigir a qualidade externa das frutas e o controle sobre todo o sistema de produção, incluindo a análise de resíduos nos frutos e estudo sobre o impacto ambiental, para realizarem suas importações (Fachinello et al., 2000).

Averrhoa bilimbi L. é uma espécie frutífera pertencente à família Oxalidaceae, popularmente conhecido como biri-biri, bilimbi, limão-japonês, limão-de-caiena e caramboleira amarela (Lima et al., 2001). É uma árvore pequena, chegando a $15 \mathrm{~m}$ de altura, com frutos tipo baga, cilíndricos apresentando cinco lóbulos longitudinais (Figura 1), mudando de coloração de acordo com o estágio de maturação, de verde a amarelada, com aumento máximo do peso e das dimensões das frutas durante este estágio (Mathew et al., 1993; Lima et al., 2001).
O biri-biri apresenta origem incerta, podendo ter se originado da Índia ou Malásia provavelmente se dispersando da Índia para outros países como o Brasil (Corrêa, 1978; Wilson, 1990; Wiersema e León, 1999). No Brasil, esta espécie é cultivada nos Estados do Rio de Janeiro, Amazonas, Pará e Santa Catarina, com distribuição e comercialização dos frutos restrita (Lima et al., 2001).

O biri-biri apresenta importância econômica na utilização da madeira e também é cultivada visando à obtenção das frutas, que contêm elevada acidez e, quando verdes, são utilizados na produção de vinagre e conservas. As frutas maduras podem ser consumidas in natura ou processadas para preparo de compotas e geleias. Bnouham et al. (2006) demonstraram que o extrato etanólico de folhas de biri-biri tem ação antidiabética, contribuindo para a redução da taxa de glicose, bem como o teor de triglicerídeos no sangue em 130\%. O suco da fruta é antiescorbútico com alto teor de ácido oxálico e ascórbico. A vitamina $\mathrm{C}$, ou ácido ascórbico, presente no biri-biri assim como em outros alimentos, participa de diversos processos metabólicos, dentre eles a formação do colágeno e síntese de epinefrina, corticoesteróides e ácidos biliares. Além de co-fator enzimático, participa dos processos de óxido-redução, aumentando a absorção de ferro e a inativação de
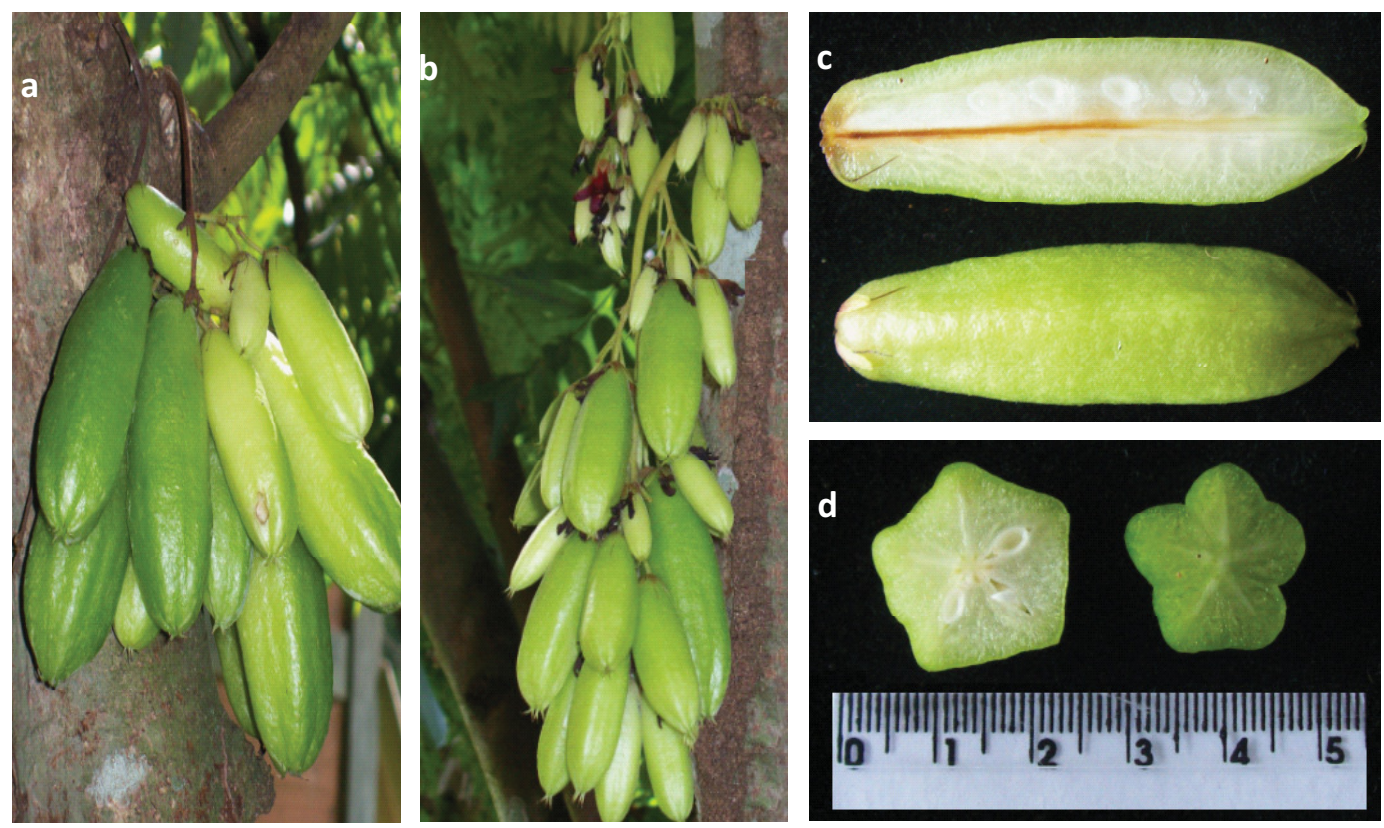

FIGURA 1: Frutos de Biri-biri. a) e b) Frutos no caule; c) corte longitudinal e d) corte transversal. 
radicais livres (Padh, 1991). Este mesmo autor, afirma que a vitamina $C$ é essencial para seres humanos, agindo como antioxidante, varredor de radicais livres e nutre as células, protegendo-as de danos causados pelos oxidantes. Os indivíduos que não ingerem vitamina $\mathrm{C}$ suficiente desenvolvem o escorbuto que causa fadiga, sangramento e má cicatrização, sendo a denominação de ácido ascórbico atribuída para referir-se à sua função na prevenção do escorbuto.

Além de seu uso medicinal, o suco de biri-biri pode ser usado ainda na remoção de manchas de ferrugem de roupas (Corrêa, 1926; 1978; Joseph e Mendonça, 1989; Lennox e Ragoonath, 1990; Wong e Wong, 1995; Wiersema e León, 1999). A composição química dos frutos pode variar de acordo com fatores ambientais, genéticos, distribuição geográfica e estágios de maturação.

O objetivo deste trabalho foi caracterizar a composição físico-química de frutos de biri-biri, em diferentes estádios de maturação.

\section{Material e Métodos}

O presente trabalho foi realizado no laboratório de Biotecnologia Vegetal do Centro de Ciências Agrárias da Universidade Federal da Paraíba, Areia - PB. Frutos de biri-biri foram coletados no município de Areia - PB e posteriormente classificados de acordo com o tamanho e coloração do fruto, sendo enquadrados em três estádios de maturação; verde, semi-maduro e maduro. A amostra de trabalho foi composta por 15 repetições por estádio de maturação.

Os caracteres avaliados foram: peso dos frutos (g), vitamina C (mg de ácido ascórbico/100g de polpa); diâmetro do fruto $(\mathrm{cm})$; número de sementes por fruto (unidade); sólidos solúveis totais ( ${ }^{\circ}$ Brix) e acidez titulável ( $\mathrm{g}$ de ácido cítrico/100g de polpa). Para a caracterização física dos frutos foram considerados: peso do fruto (PF), em gramas, obtidos através de pesagem individual do fruto em balança semianalítica; número de sementes por frutos. O comprimento e largura dos frutos foram determinados com auxílio de paquímetro. Para as análises físico-químicas, os frutos de cada estádio de maturação foram triturados em almofariz com auxilio de um pistilo sendo posteriormente peneirados para obtenção da polpa, a qual foi submetida às determinações do $\mathrm{pH}$ em potenciômetro (Digimed DM21); sólidos solúveis totais (SST) expressos em ${ }^{\circ}$ Brix, utilizando refratômetro (Abbe 1300-1720, 0-95\% Modelo 2 Waj). A acidez titulável foi determinada, titulando-se a amostra com solução de hidróxido de sódio $0,1 \mathrm{~N}$, e utilizando-se fenolftaleína como indicador expressando-se o resultado final em percentagem de ácido cítrico (Instituto Adolfo Lutz, 2005).

Todos os parâmetros mencionados foram determinados de acordo com os métodos da AOAC (1990). O experimento foi analisado no delineamento inteiramente casualizado, com 15 repetições e três tratamentos. As médias foram comparadas pelo teste de Duncan a $1 \%$ de probabilidade, usando-se o programa computacional Genes (Cruz, 2001).

\section{Resultados e Discussão}

Foram detectadas diferenças significativas $(\mathrm{p}=0,01)$, para todas as características exceto, para o teor de Vitamina C (Tabela 1). Nos três estádios as frutas apresentam pequena quantidade de sementes que variam de 12 sementes, para frutas menores, a 18 sementes nos frutos maiores (Tabela 2). Resultados semelhantes foram encontrados por Lima et al. (2001) com relação aos frutos maduros, aproximadamente 15 sementes por fruto, entretanto, para os frutos verdes, obteve-se uma média de três sementes por fruto, média esta menor que a encontrada no presente trabalho.

Quanto às variáveis: comprimento, menor e maior largura, as frutas maduras apresentaram-se maiores que nos demais estádios, com variação significativa do peso (Tabela 2). Negreiros et al. (2007), trabalhando com maracujazeiro amarelo, encontraram correlação significativa entre diâmetro e peso de frutos, indicando que pode ser praticada seleção indireta para essas características. 
TABELA 1: Resumo da análise de variância das características físico-químicas de frutos de biri-biri (Averrhoa bilimbi L.) coletados em três estádios de maturação.

\begin{tabular}{ccccccccccc}
\hline & \multicolumn{1}{c}{ Quadrados Médios } \\
\cline { 2 - 10 } F.V & $\begin{array}{c}\text { Comprimento } \\
(\mathrm{cm})\end{array}$ & $\begin{array}{c}\text { Largura } \\
\text { Menor } \\
(\mathrm{cm})\end{array}$ & $\begin{array}{c}\text { Largura } \\
\text { Maior }(\mathrm{cm})\end{array}$ & $\begin{array}{c}\text { Peso do } \\
\text { Fruto }(\mathrm{g})\end{array}$ & $\begin{array}{c}\mathrm{N}^{\circ} \text { de sementes } \\
(\mathrm{un})\end{array}$ & $\begin{array}{c}\text { Vitamina C } \\
(\mathrm{mg} / 100 \mathrm{~g})\end{array}$ & $\begin{array}{c}\text { Acidez } \\
\text { Titulavel } \\
(\%)\end{array}$ & $\begin{array}{c}\mathrm{pH} \\
\left({ }^{\circ} \mathrm{Brix}\right)\end{array}$ \\
\hline $\begin{array}{c}\text { Estádios de } \\
\text { maturação } \\
\text { CV }(\%)\end{array}$ & $21,14^{* *}$ & $0,679^{* *}$ & $1,539^{* *}$ & $1626,52^{* *}$ & $113,26^{* *}$ & $1326,62^{\mathrm{NS}}$ & $1,016^{* *}$ & $0,049^{* *}$ & $3,053^{* *}$ \\
\hline
\end{tabular}

NS e ** = Não significativo e significativo a $1 \%$ de probabilidade, respectivamente, pelo teste $\mathrm{F}$.

TABELA 2: Médias das características físico-químicas de frutos de biri-biri (Averrhoa bilimbi L.) nos diferentes estádios de maturação.

\begin{tabular}{|c|c|c|c|c|c|c|c|c|c|}
\hline \multirow[b]{2}{*}{$\begin{array}{l}\text { Estádio de } \\
\text { Maturação }\end{array}$} & \multicolumn{9}{|c|}{ Características } \\
\hline & $\begin{array}{l}\text { Comprimento } \\
\text { (cm) }\end{array}$ & $\begin{array}{c}\text { Largura } \\
\text { Menor }(\mathrm{cm})\end{array}$ & $\begin{array}{l}\text { Largura } \\
\text { Maior } \\
(\mathrm{cm})\end{array}$ & $\begin{array}{l}\text { Peso do } \\
\text { Fruto }(\mathrm{g})\end{array}$ & $\begin{array}{c}\mathrm{N}^{\circ} \text { de } \\
\text { sementes } \\
\text { (un) }\end{array}$ & $\begin{array}{c}\text { Vitamina C } \\
\text { (mg de ácido } \\
\text { ascórbico/100g) }\end{array}$ & $\begin{array}{c}\text { Acidez } \\
\text { itulável }(\mathrm{g} \\
\text { de ácido } \\
\text { cítrico/100g) }\end{array}$ & $\mathrm{pH}$ & $\begin{array}{c}\mathrm{SST}^{1} \\
\left({ }^{\circ} \text { Brix }\right)\end{array}$ \\
\hline 1 & $6,22 \mathrm{c}$ & $1,56 \mathrm{c}$ & $2,21 \mathrm{c}$ & $15,75 \mathrm{c}$ & $12,86 \mathrm{~b}$ & $50,82 \mathrm{a}$ & $1,15 \mathrm{~b}$ & $2,57 \mathrm{a}$ & $2,35 \mathrm{~b}$ \\
\hline 2 & $7,44 \mathrm{~b}$ & $1,79 \mathrm{~b}$ & $2,56 \mathrm{~b}$ & $25,26 \mathrm{~b}$ & $13,73 \mathrm{~b}$ & $41,69 \mathrm{a}$ & $1,51 \mathrm{a}$ & $2,46 \mathrm{~b}$ & $2,59 \mathrm{~b}$ \\
\hline 3 & $8,59 \mathrm{a}$ & $1,98 \mathrm{a}$ & $2,86 \mathrm{a}$ & $36,55 \mathrm{a}$ & $18,00 \mathrm{a}$ & $32,01 \mathrm{a}$ & $1,66 \mathrm{a}$ & $2,49 \mathrm{~b}$ & $3,23 \mathrm{a}$ \\
\hline DMS & 0,35 & 0,12 & 0,16 & 2,98 & 3,29 & 17,04 & 0,20 & 0,06 & 0,47 \\
\hline $\mathrm{CV} \%$ & 5,33 & 8,02 & 7,30 & 13,00 & 25,01 & 46,31 & 15,98 & 2,85 & 19,69 \\
\hline
\end{tabular}

Médias seguidas de mesma letra minúscula nas colunas e maiúsculas nas linhas e nas colunas não diferem a $1 \%$ de probabilidade pelo teste de Duncan. ${ }^{1} \mathrm{SST}=$ Sólidos solúveis totais.

Os níveis de acidez também variaram de acordo com o estádio de maturação, sendo as frutas semimaduras $(1,15)$ e maduras $(1,66)$ que apresentaram maior teor de acidez, embora ambos não tenham diferido entre si (Tabela 2). Corrêa et al. (2008) e Brunini et al (2003), trabalhando com papaya e goiaba, encontraram acidez de 0,083 e 0,408 , respectivamente. Para acidez titulável os maiores valores foram verificados nas frutas maduras com resultados decrescentes entre os estádios semimaduros e verdes (Tabela 2). De acordo com Torres et al. (2003), em frutos de carambola (Averrhoa carambola L.) ocorreu o oposto, quanto mais verde o fruto, maior a média para acidez.

Neste trabalho não houve diferença significativa entre os estádios de maturação para vitamina $\mathrm{C}$, apesar das frutas verdes apresentarem valores numéricos superiores em relação aos demais, tendo em média $50,82 \mathrm{mg} / 100 \mathrm{~g}$ para as frutas verdes, $41,69 \mathrm{mg} / 100 \mathrm{~g}$ para as frutas semi-maduras e $32,01 \mathrm{mg} / 100 \mathrm{~g}$ para as frutas maduras (Tabela 2). Os valores observados são um pouco inferiores aos apresentados por outras frutas como goiaba $(67,86)$ (Brunini et al, 2003) e caju (110) (Andrade et al, 2008). Conforme este último autor a vitamina $C$ apresenta alta sensibilidade aos fatores do ambiente $\mathrm{e}$ outros fatores instrísecos do processo de senescência. $\mathrm{O}$ conteúdo de vitamina $\mathrm{C}$ na maioria dos frutos tende a diminuir durante o processo de maturação, assim como aconteceu com estudos realizados com manga (Aina et al., 1990; Gofur et al., 1994), com acerola (Santos et al., 1999; Carvalho e Manica, 1993), cajazeiras (Pinto et al., 2003) entre outros. Em acerola, este fato pode ser atribuído, segundo Butt (1980), ao decréscimo na atuação da enzima denominada ácido ascórbico oxidase (ascorbato oxidase), isolada em acerola por Asenjo et al. (1960), os quais verificaram que a atividade enzimática nos frutos maduros é maior que nos verdes, fato que pode explicar as perdas desta vitamina encontradas no decorrer da maturação. 
Lima et al. (2001) verificaram que os frutos maduros apresentaram menores valores para ácido oxálico e maiores para vitamina $\mathrm{C}$, independentemente das condições climáticas.

Com relação ao $\mathrm{pH}$, os frutos de biri-biri apresentaram diferenças significativas, sendo a variação de 2,49 para frutas maduras, a 2,57 para frutas verdes. Em carambola tipo azedo, pertencente à mesma família do biri-biri, o pH variou de 1,25 a 2,0 (Lennox e Ragoonath, 1990).

Os valores de sólidos solúveis totais aumentam no fruto maduro em relação aos semi maduros e verdes (Tabela 2), variando de 2,35 a 3,23. Esses valores são inferiores aos encontrados por Corrêa et al. (2008), em mamão $(10,19)$ e por Brunini et al $(2003)$ em goiaba $(9,09)$. Lima et al. (2001) também verificaram que os frutos maduros maiores valores de SST independentemente das condições climáticas. Lenderman et al. (2000), Teixeira et al. (2001) e Torres et al. (2003), trabalhando com carambola, verificaram valores médios superiores aos relatados no presente trabalho.

O teor de sólidos solúveis totais é um índice de qualidade, sendo sua concentração e composição componente indispensável ao sabor e flavor do fruto. Outros parâmetros como $\mathrm{pH}$ e acidez titulável da polpa da fruta também são utilizados para indicar a qualidade dos frutos e refletem o estádio de maturação dos mesmos (Santana et al., 2004). Os dados encontrados neste trabalho corroboram com o desses autores, sendo as características aqui avaliadas indicadoras do estádio de maturação dos frutos de biri-biri.

\section{Referências}

Aina, J. O. 1990. Physico-chemical changes in African mango (Irvingia gabonensis) during normal storage ripening. Food Chemistry, 36 (3): 205-212.

Albuquerque, A. S.; Bruckner, C. H.; Cruz, C. D.; Casali, V. W. D.; Araújo, R. da C.; Moreira, A. E.; Souza, J. A. de. 2002. Possibilidade de seleção indireta para peso do fruto e rendimento em polpa em maracujá (Passiflora edulis Sims). Anais do $17^{\circ}$ Congresso Brasileiro de Fruticultura, Belém, Brasil, CD-Rom.

Andrade, A. P. S.; Oliveira, V. H.; Innecco, R.; Silva, E. O. 2008. Qualidade de cajus-de-mesa obtidos nos sistemas de produção integrada e convencional. Revista Brasileira de Fruticultura, 30 (1): 176-179.
AOAC. 1990. Official methods of analysis of the Association of Official Analytical Chemists. $15^{\text {th }}$ ed. Association of Official Analytical Chemists, Arlington, USA, 1298pp.

Asenjo, C. F.; Penaloza, A.; Medina, P. 1960. Characterization of ascorbase present in the fruit of the Malpighia punicifolia L. Federation of American Societies for Experimental Biology. Federation Proceedings, 19 (1): 1.

Bnouham, M.; Ziyyat, A.; Mekhfi, H.; Tahri, A.; Legssyer, A. 2006. Medicinal plants with potential antidiabetic activity - A review of ten years of herbal medicine research (1990-2000). International Journal of Diabetes \& Metabolism, 14: 1-25.

Brunini, M. A.; Oliveira, A. L.; Varanda, D. B. 2003. Avaliação da qualidade de polpa de goiaba 'paluma' armazenada a $-20^{\circ} \mathrm{C}$. Revista Brasileira de Fruticultura, 25 (3): 394-396.

Carvalho, R. I. N. de; Manica, I. 1993. Acerola: Composição e armazenamento de frutos. Caderno de Horticultura, 1: 1-7.

Corrêa, M. P. 1926. Dicionário das plantas úteis do Brasil e das exóticas cultivadas. Imprensa Nacional, Rio de Janeiro, Brasil, $307 \mathrm{pp}$.

Corrêa, M. P. 1978. Dicionário das plantas úteis do Brasil e das exóticas cultivadas. v.6. Imprensa Nacional, Rio de Janeiro, Brasil, $777 \mathrm{pp}$.

Corrêa, S. F.; Souza, M. S.; Pereira, T.; Alves, G. V. L.; Oliveira, J. G.; Silva, M. G.; Vargas, H. 2008. Determination of thermal diffusivity in papaya pulp as a function of maturation stage. Revista Brasileira de Fruticultura, 30 (3): 611-615.

Cruz, C. D. 2001. Programa Genes: Aplicativo computacional em genética e estatística. UFV, Viçosa, Brasil, 648pp.

Gofur, M. A.; Shafique, M. Z.; Helali-Fº, H.; Ibrahim, M.; Rahman, M. M.; Hakim, A. 1994. Effect of various factors on the vitamin $\mathrm{C}$ (ascorbic acid) content of some mango varieties grown in Rajshahi region. Bangladesh Journal of Scientific and Industrial Research, 29 (3): 163-171.

Fachinello, J. C.; Grutzmacher, A. D.; Herter, F. G.; Cantillano, F.; Mattos, M. L. T.; Fortes, J. F.; Afonso, A. P. S.; Tibola, C. S. 2000. Avaliação do sistema de produção integrada de pêssego de conserva na região de Pelotas - Safra 1999-2000. Resumos do $2^{\circ}$ Seminário de Produção Integrada de Frutas, Bento Gonçalves, Brasil, p.7884.

Instituto Adolfo Lutz. 2005. Normas analíticas do Instituto Adolfo Lutz: Métodos químicos e físicos para análise de alimentos. $4^{\text {a }}$ ed. Instituto Adolfo Lutz, São Paulo, Brasil, 1018pp.

Joseph, J.; Mendonca, G. 1989. Oxalic acid content of carambola (Averrhoa carambola L.) and bilimbi (Averroha bilimbi L.). Proceedings of the Interamerican Society for Tropical Horticulture, 33: 117-120.

Lenderman, I. E.; Bezerra, J. E. F.; Assunção, M. A. de; Freitas, E. V. de. 2000. Characterization and selection of star fruit (Averrhoa carambola L.) genotypes in Pernambuco. Revista Brasileira de Fruticultura, 22 (1): 31-35.

Lennox, A.; Ragoonath, J. 1990. Carambola and bilimbi. Fruits, 45 (5): 497-501.

Lima, V. L. A. G. de; Mélo, E. de A.; Lima, L. dos S. 2001. Physicochemical Characteristics of Bilimbi (Averrhoa bilimbi L.). Revista Brasileira de Fruticultura, 23 (2): 421-423. 
Mathew, L.; George, S. T.; Babylatha, A. K.; Geetha, C. K. 1993. Flowering and fruit development in bilimbi (Averrhoa bilimbi L.). South Indian Horticulture, 41 (1): 41-42.

Negreiros, J. R. S.; Álvares, V. S.; Bruckener, H.; Morgado, M. A. D.; Cruz, C. D. 2007. Relação entre características físicas e o rendimento de polpa de maracujá-amarelo. Revista Brasileira de Fruticultura, 29 (3): 546-549.

Padh, H. 1991. Vitamin C: Never insights into its biochemical functions. Nutrition Reviews, 49 (3): 65-70.

Pinto, W. S.; Dantas, A. C. V. L.; Fonseca, A. A. O.; Ledo, C. A. S.; Jesus, S. C.; Calafange, P. L. P.; Andrade, E. M. 2003. Caracterização física, físico-química e química de frutos de genótipos de cajazeiras. Pesquisa Agropecuária Brasileira, 38 (9): 1059-1066.

Santana, L. R. R.; Matsuura, F. C. A. U.; Cardoso, R. L. 2004. Genótipos melhorados de mamão (Carica papaya L.): avaliação sensorial e físico-química dos frutos. Ciência e Tecnologia de Alimentos, 24: 217-222.

Santos, A. R. L.; Reinhardt, D. H.; Silveira, W. R.; Oliveira, J. R. P.; Caldas, R. C. 1999. Qualidade pós-colheita de acerola para processamento, em função de estádios de maturação e condições de armazenamento. Revista Brasileira de Fruticultura, 21 (3): 365-371.
Teixeira, G. H. A. T.; Duringan, J. F.; Donadio, L. C.; Silva, J. A. A. 2001. Caracterização pós colheita de seis cultivares de carambola (Averrhoa carambola L.). Revista Brasileira de Fruticultura, 23 (3): 1-7.

Torres, L. B. V.; Figueirêdo, R. M. F.; Queiroz, A. J. M. 2003. Caracterização química de carambolas produzidas em região semiárida do Nordeste brasileiro. Revista Brasileira de Produtos Agroindustriais, 1: 43-54.

Wiersema, J. H.; León, B. 1999. World economic plants: A standard reference. CRC Press, Boca Raton, USA, 749pp.

Wilson, C. W. III, Shaw, P. E.; Knight, R. J. Jr. 1982. Analysis of oxalic acid in carambola (Averroha carambola $\mathrm{L}$.) and spinach by high-performance liquid chromatography. Journal of Agricultural and Food Chemistry, 30 (6): 1106-1108.

Wong, K. C.; Wong, S. N. 1995. Volatile constituents of Averrhoa bilimbi L. fruit. Journal of Essential Oil Research, 7 (6): 691693. 